\title{
The Goal Triad in Games. A Conceptual Map and Case Studies
}

\author{
La tríada de los objetivos del juego. Mapa conceptual \\ $y$ estudio de casos
}

FILIP KOBIELA

University of Physical Education in Cracow (Polonia)

Artículo recibido: 21 septiembre 2015

Solicitud de revisión: 3 diciembre 2015

Artículo aceptado: 14 enero 2016

\begin{abstract}
The paper is devoted to detailed analysis of the notion of goal in games. It is argued that Suits' analysis which provides a distinction between prelusory goal and lusory goal is insufficient, and thus introduction of a third kind of goal is necessary. I suggest to call this third kind of goal institutional goal.The paper discusses the definition of this kind of goal as well as its relations to other kinds of goals in games and other elements of game-playing. These three goals create the goal triad, a conceptual map of all possible goal-related situations. Both Venn diagrams and Euler diagrams are used to represent this triad. Various fields of these diagrams, which represent a spectrum of specific situations that occur in games, are illustrated by case-studies, taken mainly (although not exclusively) from the history of association football (soccer).
\end{abstract}

Keywords: sport, game, goal, Hand of God, Suits

Resumen

El artículo plantea un análisis detallado de la noción de objetivo de los juegos. Se argumenta que el análisis de los juegos de Suits, que ofrece una distinción entre objetivo lúdico y meta pre-lúdica, es insuficiente, por lo que es necesaria la introducción de un tercer objetivo. A este tercer objetivo sugiero llamarlo meta institucional. El artículo analiza la definición de este tipo de objetivo, así como sus relaciones con los otros tipos de objetivos y elementos del juego. Estos tres objetivos constituyen la tríada de objetivos, un mapa conceptual de todas las relaciones posibles entre objetivos. Para representar la tríada se emplean los diagramas de Venn y de Euler.Varios campos de estos diagramas, que representan un espectro de situaciones específicas que suceden en los juegos, se ilustran con estudios de casos, tomados principalmente (aunque no exclusivamente) de la historia del fútbol.

Palabras clave: deporte, juego, objetivo, Mano de Dios, Suits 


\section{INTRODUCTION}

Roger Caillois, one of the founders of the philosophical theory of games, play and sport, had aptly observed that games are governed by a separate «legislature» suspending ordinary rules of everyday life. Research, which would assume a mature method to attack the ethical issues concerning sports ought to examine specific problems emerging from the clash of two separate worlds of rules - everyday and game-specific. The issues relate to the ontological structure of sport activities. This duty is, inter alia, expressed in a remark made by S. Kretchmar (1988) that «soft metaphysics is a precursor to good sport ethics». One can, however, get an impression that part of sport ethics (i.e. the practical philosophy of sport) marginalizes these principal research belonging to the theoretical philosophy of sports. Thus, I would like, to some extent, fill this gap, by examining the problem of the structure of games and sports, and more specifically - by paying particular attention to the issue of goals. It is a basic problem for both, praxeological as well as ethical analyses of activities occurring within the framework of sports. I am convinced that some relating resolutions bearing ontological character have ethical consequences. Ontology, thus, plays a similar role to metaethics: it does not analyse the ethical problems directly, however leads to some conclusions of ethical nature.

\section{THE ESSENTIAL FEATURES OF SPORT}

The first task of theoretical philosophy of sport is to explain the nature and structure of sport. Although the very existence and need for an exact definition of sport is still debatable, there is a common agreement that competitive sport events on elite level are activities that are (among other things):

1) Goal directed

2) Rule-governed

3) Institutionalized

These three facts will guide us in an analysis of the complex issue concerning the idea of goal in games. The first of these facts - that games are goal-oriented activities - is reflected in the very basic notion of prelusory goal. The fact that achieving the prelusory goal in games is rule-governed is reflected in the notion of a lusory goal. Finally, the institutionalized as- 
pect of games is reflected in the notion of, nomen omen, an institutional goal.

This paper sets a goal to analyse the notion of goal in sport. This task is the utmost primary task of theoretical philosophy of sport. Although fundamental, the notion of the goal in sport is still not fully explained, which results in conceptual confusions. One example of such a conceptual confusion (as shown below) is the ambiguity of the term "ghost goal». The task of conceptual analysis is to eliminate all such ambiguities.

In my further analyses I assume the master philosophical theory of games to be the game theory of Bernard Suits, proposed by him in his opus magnum - The Grasshopper. Games, Life and Utopia (Suits, 1978), presented in a series of articles, with a particularly important The Elements of Sport (Suits, 1973). I use the term philosopbical game theory due to the risk of equivocation: the expression game theory can be understood as referring to both - the undertaken examinations on nature, structure and typology of games in a lusory sense, as well as to the mathematical theory of games, which, in fact, is the formal theory of strategy, not only present in games in a lusory sense, but in all conflict situations. The philosophical theory of games is of basic character here, providing the real definition of games in a lusory sense, specifying their structure, and allowing for further, more detailed research. As there are usually some conflict situations in games in a lusory sense, followed by some strategies of action, the mathematical theory of games also provides knowledge on these type of games. However, mathematical research on the strategies in games and sports is situated on a different level than philosophical research.

Let us note that Suits' theory is dedicated to the structure of games, and although the text of The Grasshopper mentions the examples of various sport disciplines, the analysis of relations between the meanings of the terms game and sport is not undertaken by Suits in this work. There is a spectrum of approaches as to which of the sport disciplines are, in fact, games. The «minimalistic» approach is the one drawn from the ordinary use of these words. Indeed, only some of the sports could be called games, and there is no clear cut boundary between the sports that are games, and the sports that are not games. We can only assume that the basic difference between these two groups of sports would be the existence of direct competition based on interaction. Unfortunately, the ordinary language is not consistent in this case. The weakest link of this approach is - inherited after the inconsistency of the ordinary language - the lack of criteria to draw a clear demarcation line between sports that are games and sports 
that are not games. Initially Suits (1973) offered a «maximalistic» solution, which included every sport in the domain of games, later, however, he withdrew his idea (Suits 1988), offering other, intermediate solution: most of sports are games, although there are also exceptions in the form of the so-called judged-sports, such as diving or figure skating, which are not games. I will not undertake a more profound analysis of this problem here, and $I$ assume for the need of further analysis, that at least the majority of sports should be considered games in the Suits' sense; the results of the following analyses are therefore applicable for this broad group of sports. Moreover, they are also binding for those games, which do not have a clear sport status (chess and other so-called mind games).

\section{SUITS' ANALYSIS OF THE NOTION OF GOAL IN GAMES}

In Suits' theory there are three distinguishable goals involved in game playing; it is important to note that these are not merely three different formulations of one and the same purpose. According to Suits (1978:36), if we were to ask a long distance runner for his purpose in entering a longdistance race, he might say any one of these three things:

1) To participate in a long distance race

2) To win the race

3) To cross the finish line ahead of the other contestants. ${ }^{1}$

It is crucial to note that goal (3) is the simplest of the triplet [of goals]: both goal (1) and goal (2) presuppose it, whereas (3) does not presuppose either of the other two.Thus according to Suits (1978:36) only goal (3) has the claim to be regarded as an elementary component of game playing; goal (1) and goal (2) are complex components - they can be defined only after the disclosure of additional elements. Since goal (1) is not a part of the game at all, the further analysis of Suits focuses on the distinction be-

1 Suits' paradigmatic example of games - a foot race, which he uses for introducing the distinction between prelusory goal and lusory goal, belongs to the domain of competitive games. This domain also contains other games that play important function in Suits' analyses, like golf, boxing or chess. Within the scope of the paper, I'll remain in the limits of this domain, because of its special importance for sport. However, Suits' theory of game-playing also encompasses non-competitive games. In the structure of the games belonging to the latter domain - there is - by definition - a distinction between prelusory and lusory goal that could, in turn, be complemented by the institutional goal. For the contradistinction between competitive versus non-competitive games in Suits' sense, see Vossen (2004). 
tween goal 2) - called prelusory goal and goal 3), called lusory goal (form Latin ludus - game).

Let us note that the three possible answers to the question posed by Suits on the purpose of participating in the race, in no way exhaust the possible spectrum of answers. The spectrum is virtually unlimited, and a typical example of an answer varying from the ones provided by Suits is, for instance, «finish the race and not take the last place», or «at the initial phase of the race set an appropriate pace, and not continue it later» (case of some pacemakers). It is, however, understood that the answers indicated by Suits are not only typical, but also play important heuristic functions in further analyses. According to Suits goal (3) «to cross the finish line ahead of the other contestants» and other goals of this kind

may be described generally as a specific achievable state of affairs. (...) By omitting to say how the state of affairs in question is to be brought about, it avoids confusion between this goal and the goal of winning. (...) I suggest that this kind of goal be called the prelusory goal of a game, because it can be described before, or independently of, any game of which it may be, or come to be, a part. In contrast, the goal of winning can be described only in terms of the game in which it figures; and winning may accordingly be called the lusory goal of a game (Suits, 1978: 36-37).

As it can be noted, pointing to the difference between winning the race - lusory goal (being first on the finish line by following the rules), and the prelusory goal - being the first on the finish line, not necessarily by following the rules (or even without participating in the race) is quite intuitive, just like the terminology adopted by Suits originating in ludus, a classic term in culture sciences. And still, the clear analysis of this distinction is a significant achievement of Suits, which is particularly well visible in relation to the conceptual confusion occurring in some research neglecting this distinction.

\section{SUITS' DEFINITION OF GAME PLAYING}

In his definition of game playing Suits thus originates with the concept of prelusory goal. It gives this definition a distinct character, exposing the function of rules in games (particularly a certain kind of rules, i.e.constitutive rules). As it turns out, games are paradoxical activities, i.e. they use certain means to achieve a set goal, which, in fact, make it more difficult to achieve this goal.Activities in which means are used to achieve the goal, make them more difficult to reach at the same time. This phenomenon, 
exposed by the theory of Suits (but also mentioned earlier by R. Caillois), is set in motion by constitutive rules. However, in order to be capable to capture their specific function, one needs to be aware of the basic concept of prelusory goal. Suits' complete definition of game playing is as follows:

To play a game is to attempt to achieve a specific state of affairs [prelusory goal], using only means permitted by rules [lusory means], where the rules prohibit use of more efficient in favour of less efficient means [constitutive rules], and where the rules are accepted just because they make possible such activity [lusory attitude]. (Suits, 1978: 41)

Each of the four conditions in this definition is a necessary (but not sufficient) condition to be a case of game playing, and the conjunction of the four conditions is a sufficient condition to be a case of game playing.

It should be noted that the concepts of prelusory goal and constitutive rules are combined with each other being responsible for the paradoxical nature of games.After all, there are many paradoxical activities that are not of ludic nature, therefore, the next necessary condition to be a game is lusory attitude, corresponding to the voluntary nature of limitations imposed by constitutive rules. In the face of these terms the short form of the definition of game playing becomes more comprehensible (Suits, 1978: 41): playing a game is the voluntary attempt to overcome unnecessary obstacles.

Let us see that Suits defines a certain activity: game playing, strictly speaking, does not provide a definition of the product of this activity, i.e. the game itself. However, such definition is an obvious result of the given game playing definition.After Berman (2013: 1), we can say that according to Suits:

games are rule-governed activities in which $(a)$ a participant pursues a prelusory goal, $(b)$ using only those means permitted by the rules, $(c)$ where those rules exclude more efficient in favor of less efficient means of realizing the prelusory goal, and $(d)$ in which the participant accepts the limitations to make the activity possible.

The definition aims to translate Suits' own definition of game playing into a definition of the game (Berman, 2013: 1).

After the presentation of the definition of game playing and its counterpart the definition of the game, we can move on to discuss an example of implementing these definitions. The consequences of Suits' theory prove to be highly non-trivial, and the paradoxical nature of games may seem especially surprising. Indeed, participating in as well as observing games are naturally oriented on the lusory goal, hence the deeply hidden, 
essential mechanism of the game, and in particular the relation between prelusory goal and constitutive rules is somehow left unnoticed. The innovativeness of Suits' analysis consists then in revealing this hidden mechanism of games. Let us now take a look at an example of analysis provided by Suits himself. Foot races are typical games in Suits' sense - they satisfy all necessary and sufficient conditions of being a game:

1. Participant engages in an activity directed towards bringing about a specific state of affairs - to cross the finish line before other contestants (prelusory goal);

2. Participant engages in this activity using only means permitted by rules (lusory means);

3. Where the rules prohibit more efficient in favour of less efficient means (constitutive rules) - e.g it is useful but proscribed to trip a competitor in a foot race; or to use a means of public transport in a marathon race;

4. Participant accepts the rules just because they make such activity possible - participant accepts the rules of the foot-race so that she can attend it (lusory attitude).

As we can see, there is no doubt that races meet all the postulated conditions of being a game.Then, races are games in the sense of Suits. However in ordinary language, the word "game» will not be used to describe races. $^{2}$ Suits' definition is not then a definition encompassing the colloquial use of the word "game» (or to use Wittgenstein's idiom, it does not respect all the rules of standard language game with the word "game»). It is also not a definition designing an entirely new meaning of the word "game», since nearly all activities described as games in ordinary language meet the definition. We can then agree that Suits' definition is a definition regulating the meaning of the word "game». Let us note that, independently from terminological considerations, the definition encompasses here a certain uniform, specific phenomenon, and at the same time clarifies its structure. It, thus, provides a resourceful cognitive insight into certain activities, whether they are called games or not, and what is more, this insight is also entirely independent of the fact that Suits called the phenomenon defined by him "game playing». As it turns out, the considerations on the relation of Suits' definition to everyday language comprehension do not

2 Perhaps, calling all the competitions of Olympic Games "games» is an exception to that. 
question its usability for the philosophical game theory, as well as philosophical sport theory. There is no doubt that Suits' research represents a leap forward for the development of the philosophy of sports and is its master achievement, as evidenced by the influence exerted. However, the inspiring research of Suits has its limitations too, and further in the paper I will try to point out one of them and offer another solution.

\section{INEFFICIENCY OF SUITS' ANALYSIS OF THE NOTION OF GOAL IN GAMES}

The cause of inefficiency of Suits' analysis is the ambiguity of the term "win» in goal (2) - to win the race. In order to reveal this ambiguity let us analyse the infamous case of Rosie Ruiz. This marathon runner has appeared first on the finish line of the 84th Boston Marathon in 1980. In consequence she was declared as the winner of the race. However, her extraordinary achievement (2:31:56) raised some suspicions. First, she seemed not to be tired at the finish line; second, no one could recall seeing her during a race. Furthermore, she also did not appear in any pictures or video footage. After the investigation she was disqualified, because she could not possibly have run the entire course (Amdur, 1980).

In Suits' terms, although Rosie Ruiz has achieved the prelusory goal of the marathon (to be the first on the finish line), she has not achieved the lusory goal of the marathon (because she used forbidden means to achieve prelusory goal, i.e. in fact she had not won the race). But before the disqualification (on the grounds of detecting the act of cheating) she was declared as the winner of the race, and - one might say - she was (in a sense) the winner of the race. Thus «to win a game» might mean:

$\mathrm{W}_{1}$ : «to achieve a lusory goal of the game».

$\mathrm{W}_{2}$ : «to be declared (by officials) a winner of the game».

Because $\mathrm{W}_{2}$ requires officials, winning in $\mathrm{W}_{2}$ sense might be called official or institutional goal of game. The ideal of referring consists in the identity of $\mathrm{W}_{1}$ and $\mathrm{W}_{2}$, and in fact they usually coincide. However, these two goals are conceptually different (official decision might be incorrect). As Suits did not approach the institutional problem of acknowledging victory in games (however, he did undertake (1973) the problem of games institutionalization as a necessary condition to be a sport), his analysis does not take into ac- 
count winning in the $\mathrm{W}_{2}$ sense. However, neglecting the ambiguity of the term «to win» exposes us to making the mistake of equivocation.

Let us then juxtapose the solution of Suits (I will call it The Triplet of Goals) with its proposed modification (The Goal Triad). I will adopt the following symbols: $\mathrm{LG}=$ Lusory goal; $\mathrm{PLG}=$ Prelusory goal; IG = Institutional goal .

Table 1

The Triplet of Goals vs The Goal Triad

\begin{tabular}{|c|c|}
\hline The Triplet of Goals & The Goal Triad \\
\hline $\begin{array}{l}\text { 1/ to participate in a long distance } \\
\text { race }^{3}\end{array}$ & $\begin{array}{l}\text { PLG/ to cross the finish line ahead of } \\
\text { other contestants }\end{array}$ \\
\hline $\begin{array}{l}2 \text { / to win the race (to achieve } 3 \text { / } \\
\text { only by means permitted by the } \\
\text { rules) (LG) }\end{array}$ & $\begin{array}{l}\text { LG/ to achieve PLG only by means per- } \\
\text { mitted by the rules } \\
\text { - lusory sense of winning; }\end{array}$ \\
\hline $\begin{array}{l}\text { 3/ to cross the finish line ahead of } \\
\text { other contestants' (PLG) }\end{array}$ & $\begin{array}{l}\text { IG/ to be declared a winner by author- } \\
\text { ized officials } \\
\text { - institutional sense of winning; }\end{array}$ \\
\hline
\end{tabular}

The goal of participating in the race can be supported by an association with Coubertine's ideology. However, Suits himself neglects it, focusing on the key distinction between the prelusory and lusory goals. The order of the analysed goals is specific: right after participation, the intuitively guided lusory goal emerges, whereas, the prelusory goal, which is fundamental, but the most difficult to discover, proceeds last.The order of presenting the goals by Suits is probably intended to reflect the order of our intuitions.

As opposed to the order in Suits' Triplet of Goals, the Goal Triad originates with the most elementary goal, which is the brute, prelusory goal, moves through the rule-saturated lusory goal and ends with the most complex, institutional goal. The order of presentation is to reflect ontological rather that epistemological nature of the structure.

After introducing the distinction between the institutional sense of winning (institutional goal) and winning in the lusory sense (lusory goal), and taking into account the prelusory goal, we have all the elements needed to reveal the whole structure of goal in games. We are also in the position to

3 Suits claims that this kind of goal "may be called a lusory goal, but a lusory goal of life rather than of games" (Suits, 1978: 37). 
present the ongoing relationships between them. For that purpose I will first use the Venn's diagram (this type of diagram was used by Suits in his analysis of the relation between game, sport and play in The Tricky Triad), and then I will also use the Euler's diagram. ${ }^{4}$

\section{THE GOAL TRIAD (VENN DIAGRAMME)}

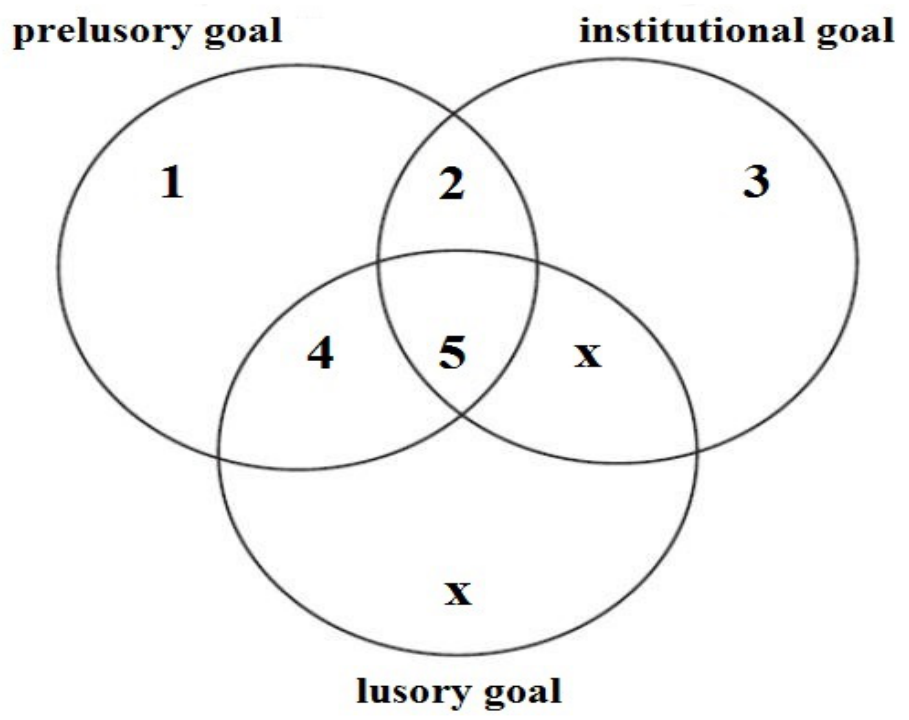

Figure 1

Venn diagramme

Before I start the general overview of the meaning of particular areas, I would like to present the operation of the diagram on the example of a partial goal of soccer - scoring a goal.

1: Rightly disallowed goal

2: Allowed but invalid goal

3: Non-existent goal

4: Disallowed (but correctly) scored goal

5: Rightly allowed goal (= proper goal)

$\mathrm{X}$ : Logically impossible combinations.

4 This type of diagram was used by Meier (1988:26) in his polemics with Suits. 
The first area presents a situation in which the prelusory goal is achieved, however it is not achieved in accordance with the rules, thus we do not deal with an achievement of a lusory goal. This fact is aptly recognized by the referee, and as a result the institutional goal is not achieved. It is a very common, and entirely correct situation - a legitimate rejection of the lusory goal, despite the fact that the prelusory goal has been realized.

Area 2 represents a situation similar to 1 (realizing the prelusory goal without realizing the lusory goal), where, however, there is an error in refereeing, which leads to the wrongful recognition of the lusory goal. Certainly, such situations should not be happening, however, they sometimes do happen (see below, the so-called «Hand of God»). It should be noted that violating the constitutive rules - i.e. the attempt to «shortcut» the process of achieving the prelusory goal - is the fundamental form of foul play.

The third area represents a situation, where both lusory and prelusory goals have not been achieved, yet there was a decision of the referee recognizing the realization of the lusory goal. How is this possible? I think that typical situations of this kind are caused by measurement error and occur, when the state of affairs considered to be the realization of prelusory goal, was in fact very close to the realization of prelusory goal. For instance in tennis, it could mean recognizing the ball, which hit out, but right next to the line as a ball, which hit the line, and thus hit the court. It should be noted that the wrong decision of the referee represented in area 3 is based on the fact that in reality the prelusory goal was not achieved, and thus, $a$ fortiori, the lusory goal was not achieved as well. These decisions can, however, be doubly incorrect: in some situations, even if the prelusory goal was realized, the lusory goal would not be achieved due to the additional breach of constitutive rules.

Area 4 represents a situation, in which the prelusory goal is achieved by following the rules, thus the lusory goal is realized as well, however, this fact is not recognized by the referee. It is the reversal of situation 2, which also sometimes occurs in games. It could be portrayed by an example of the disallowed goal in the England-Germany match during World Cup 2010.

Area 5, common for all three moments creating the complete concept of goal in games, consists of a virtual optimum: the right recognition of both pre- and lusory goals. Area 5, similarly to area 1, and unlike other previously discussed areas 2,3 , and 4 represents a situation, in which we deal with the correct decision of the referee.

And at last, the areas marked with $\mathrm{X}$ are empty, i.e. they do not represent any possibility that could be realized in games. This is because, by virtue of 
definition, achieving the lusory goal assumes achieving the prelusory goal, it is then logically impossible to achieve the lusory goal without achieving the prelusory goal. The line separating areas marked with $\mathrm{X}$ does not carry any meaning.

However, I need to point to a certain reservation here.A reservation that casts light on a certain fundamental feature of Suits' theory. The distinction between prelusory and lusory goals refers to simple games, such as races, i.e. these that have some kind of homogeneous character, or to individual partial goals in complex games, such as football or tennis. Thus Suits' analysis applies only to "partial goals" in complex games (by a complex game I understand a game, in which an ultimate goal consists of many partial goals). In such complex games to reach an ultimate goal means to score more valid points; and Suits' conceptual machinery starts when we are dealing with the question "what does it mean to score a valid point?»."

\section{THE GOAL TRIAD (EULER DIAGRAMME)}

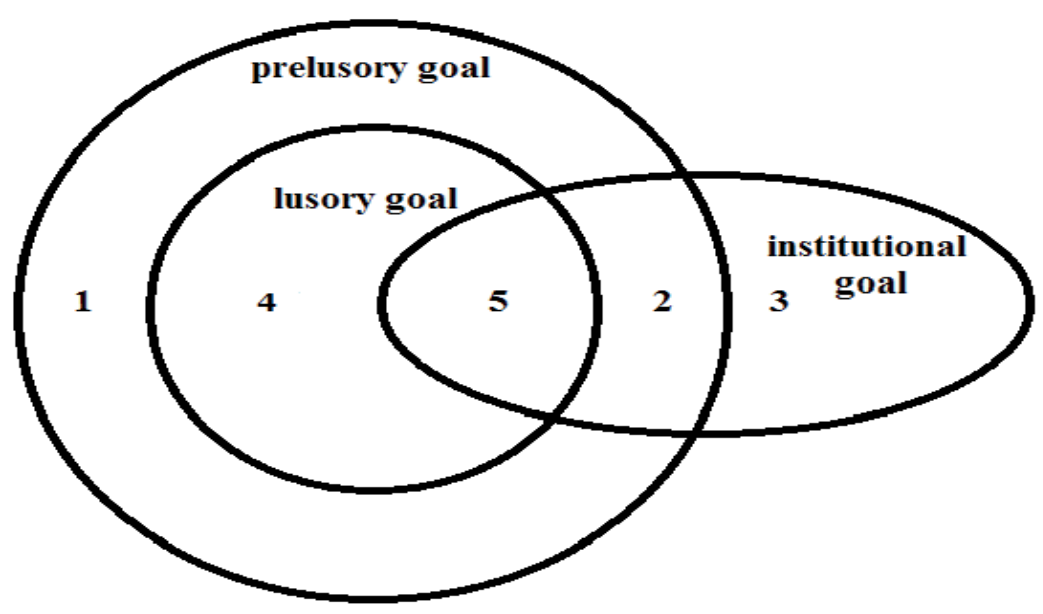

Figure 2

Euler diagramme

5 I would like to thank Alfred Archer for attracting my attention to this problem. 
Numbering and meaning of individual areas stay the same. On the example of soccer's partial goal - scoring a goal:

1: Rightly disallowed goal

2:Allowed but invalid goal

3: Non-existent goal

4: Disallowed (but correctly) scored goal

5: Rightly allowed goal (= proper goal)

The Euler diagram clearly shows that the extension of the concept of the lusory goal is the subset of the extension of the notion of prelusory goal (every LG is a PLG). The set representing the institutional goal intersects this structure in such a way that a maximum number of combinations (5) granted by the diagram is created.

Armed with the conceptual apparatus that I call «the Goal Triad» we are in the position to properly analyse the situations such as the aforementioned infamous goal scored by Diego Maradona in the quarter finals of 1986 World Cup and known as the «Hand of God». ${ }^{6}$ Maradona managed to place the ball in the opponents' goal, yet he did that by breaking the constitutive rules (with his hand), in such a way, however, that it was not noticed by the referees. In the end, then, this goal scored by hand was recognized, and significantly impacted the final result, which was beneficial for Maradona's team.

It should be noted that the initial difficulty already lies in the paradoxical statement that Maradona «scored a goal with his hand». Suits' analysis is sufficient to determine that the statement is true, if by the "goal» we understand the prelusory goal, and false, if by the «goal» we understand the lusory goal. It does not however include an equally important institutional aspect.

The «Hand of God» (HG) was an event that has occurred during a game, and which can be characterized by the following three statements:

1) It is an instance of an achievement of a prelursory goal in soccer (The ball crossed the goal line);

2) It is not an instance of an achievement of a lusory goal in soccer (The means used are prohibited by the constitutive rules of soccer);

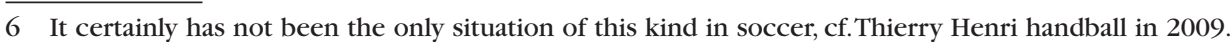


3) It is an instance of an achievement of an institutional goal in soccer (The goal was recognized by the referee).

Formally: HG - PLG \& HG - LG \& HG - IG

\section{A GHOST (PHANTOM) GOAL}

A ghost goal, also known as phantom goal, is a term used in soccer to describe a questionable decision «usually involving incertitude or controversy as to whether or not a ball crossed the goal line.A ghost goal can be awarded without the ball ever crossing the goal-line and, conversely, the term can be applied when the ball crosses the goal-line unseen by the referee» (Ghost Goal, n.d.). A case of a goal awarded without the ball ever crossing the goal-line is represented in the Goal Triad as area (3) - «nonexistent goal» (NEG).

Formally: NEG - PLG \& NEG - LG \& NEG - IG

A case in which the ball crosses the goal-line unseen by the referee is represented in the Goal Triad as area (4) - disallowed but correctly scored goal (disallowed goal - DG). As we can see, NEG and DG are two radically different situations, and identifying them with the use of one term can be highly confusing. The above analysis allows not only for precise diversification of the concepts, but also for noticing the relations between them.

Formally: DG - PLG \& DG - LG \& DG - IG

\section{THE GOAL TRIAD AND THE ESSENTIAL FEATURES OF SPORT}

After formulating the theory explaining the issue of goals in games and illustrating it with examples, I would like to mention a more general problem, which casts additional light on presented results. Let us now return to the comment made before, which relates to significant features of sport. The Goal Triad is grounded in the essential features of sport: 1) the fact that sport is goal directed - is reflected in the elementary notion of prelusory goal (PG);2) the fact that sport is rule-governed is reflected in the fact that achieving the prelusory goal in games is rule-governed (lusory goal is saturated by the game rules) (LG) 3) the fact that sport is institutionalized (refereed by authorized officials) is reflected in the notion of institutional goal (IG). I believe that the above applicability is not accidental, but a result of an adequate analysis of goal structure in games. 


\section{CONCLUSION}

Having begun my research with the analysis of Suits, who proposed the analysis of goals in games that can be called the Triplet of Goals, I suggest to implement a correction, taking into account the institutional aspect of games and sports. I argue that the framework proposed by me, which I would like to call The Goal Triad, is the correct description of the complex problem of goal in institutionalized games. Complementing the traditional Suits' distinction into lusory and prelusory goals with the notion of an institutional goal allows for precise analysis of some difficult cases, such as «the Hand of God» or "ghost goal». Representing the goals' structure in the form of diagrams allows for a convenient overview of all the possibilities in question. Relevant content presented on both diagrams (Venn's and Euler's) is equivalent, and the only variation is their way of presentation; an advantage of Euler's diagram is its simplicity.

\section{REFERENCES}

Amdur, N. (1980): «Who is Rosie Ruiz», New York Times, April 2.

BERMAN, M. N. (2013): «Sprints, Sports, and Suits», Journal of the Philosophy of Sport, Vol 40, Issue 1, pp. 163-176.

Kretchmar, R. S. (1998): «Soft metaphysics: a precursor to good sports ethics», in Mcnamee, M. J. \& Parry S. J. (eds.) (1998): Ethics and Sport, London and New York, E \& FN Spon.

MeIER, K. (1988): «Triad Trickery: Playing with Sport and Games», Journal of the Philosophy of Sport, XV, pp. 11-30.

N. D. «Ghost goal», Wikipedia, https://en.wikipedia.org/wiki/Ghost_goal (accessed September 20, 2015).

Suits, B. (1973): «The Elements of Sport», in Osterhoudt, R. (ed.) (1973): The Philosophy of Sport: A Collection of Essays, Springfield, IL, Charles C. Thomas.

SuITs, B. (1978): The Grasshopper: Games, Life and Utopia, University of Toronto Press.

Suits, B. (1988): «Tricky Triad: Games, Play and Sport», Journal of the Pbilosopby of Sport, XV, pp. 1-9.

Vossen, D. (2004): «The Nature and Classification of Games», Avante, Vol. 10, Issue 1, pp. 53-68. 